\title{
The solubilization and extraction parameters of erythromycin from aqueous phase into mixed AOT/SB3- 18 reverse micelle phase
}

\author{
S. N. Mohamad-Aziz, A. M. Mimi Sakinah
}

Faculty of Technology, Universiti Malaysia Pahang, 26300 Gambang, Pahang, Malaysia. Article Info: Submitted on March 20, 2017, Accepted on June 20, 2017.

\begin{abstract}
A liquid anionic-zwitterionic surfactant-based aqueous two-phase extraction was developed and applied for the extraction of erythromycin. Erythromycin solubilization from aqueous to reverse micelle phase was studied. Zwitterion SB3-18 surfactant was added to ionic solution of bis(2-ethylhexyl) sulfosuccinate sodium salt (AOT) to form an organic mixed micellar phase. Erythromycin was then added to the mixtures and two clear phases were formed. The parameters affecting erythromycin solubilization including AOT concentration $(20.0-120.0 \mathrm{~g} / \mathrm{L})$, zwitterion concentration $(6.0-16.0 \mathrm{~g} / \mathrm{L}), \mathrm{NaCl}$ concentration $(0.0-25.0 \mathrm{~g} / \mathrm{L})$ and aqueous $\mathrm{pH}(6.0-9.0)$ were investigated via statistical software. Solubilization of erythromycin into mixed reverse micelle could be easily evaluated by the measurement of erythromycin concentration in the organic phase. The results showed that AOT and zwitterion concentration governed the erythromycin solubilization by a factor of 4.562 based on the Pareto chart.
\end{abstract}

Keywords: Solubilization; Erythromycin; Mixed micellar phase.

\section{Introduction}

Erythromycin has an established niche as a macrolide antibiotic which is highly effective to cure a variety of pathogenic infections, preferable due to its low sideeffects. Often, it contributes in the development of second and third generation of semi-synthetic derivatives of erythromycin that further broaden its microbiological features as macrolide antibiotics. ${ }^{1}$ Aclassic approach on producing erythromycin is by isolation from Saccharopolyspora through fermentation process. ${ }^{2}$ Subsequently, erythromycin will undergo a series of purification steps from the fermentation broth, in which include filtration (removal of biomass), extraction (recovery) and crystallization (purification). In the industry, butyl acetate solvent extraction is one of the prominently used techniques. However, the drawbacks associated with solvent extraction are high consumption of organic solvent and relatively expensive operational cost. $^{3}$ Therefore, it is very critical to explore a new alternative method in order to establish a successful erythromycin recovery process.

Interestingly, a growing body of research in liquidliquid extraction has emerged with reverse micellar extraction, which recently becomes highly favorable for obtaining biological products. Central to the entire discipline of reverse micelle extraction is the ability of biochemicals including amino acids, proteins, enzymes, and nucleic acids to solubilize in the micelle components, which then could be recovered from such

Corresponding Author: A. M. Mimi Sakinah

Email: mimisakinah@gmail.com, Fax: ++609-549 2889. solutions without losing its microbial utility. ${ }^{4}$ Reverse micelles system consists of several components including surfactant, co-surfactant, oil, and water. As a whole, they make up a group of surfactant molecules with the hydrophilic part pointing inwards and dissolve in a continuous organic solvent medium. ${ }^{5}$ Reverse micelle technique is performed based on two steps: i) a target protein is selectively solubilized into the organic phase (forward extraction), and ii) the protein is subsequently stripped into the aqueous phase (backward extraction) by adding fresh aqueous buffer, also called stripping solution. However, the issue with reverse micelle extraction depends upon the interaction of mixed factors that influence the capability of protein solubilization. The state and concentration of the target protein, $\mathrm{pH}$, the concentration and species of ions, type and concentration of surfactant, and the composition of reverse micelles are the preliminary factors in reverse micelle extraction. ${ }^{6}$

Reverse micelle is of much interest among researchers in protein extraction, owing to its impressive potential for continuous operation and scaling up. ${ }^{7} \mathrm{~A}$ recent development in this subject has reported that a flexible interface could be inaugurated with the addition of second surfactant into the ionic surfactant. ${ }^{8}$ One of the most significant current discussions is a mixed reverse micelle surfactant (MRMS), that combines the function of ionic and zwitterion surfactants to enhance the physicochemical properties of the interface. 


\section{Chemical Engineering Research Bulletin 19(2017) 123-128}

Another research has appointed that mixed reverse micelles possess better synergistic performance. ${ }^{9}$ In the present paper, we have attempted the use of mixed reverse micelle from ionic AOT and SB3-18 zwitterion surfactant to extract erythromycin from the aqueous phase, purposefully to evaluate the extraction performance by combining two types of surfactant in antibiotic extraction.

\section{Chemicals}

In this research, erythromycin, sodium bis(2ethylhexyl) sulfosuccinate (AOT) and 3-(N,NDimethyloctadecylammonio) propane sulfonate (SB318) were obtained from Sigma Aldrich. Isooctane (HPLC grade) and $\mathrm{KCl}$ were purchased from Merck, Germany. All other chemicals of analytical grade were used for the experiments. Deionized water was used to prepare all aqueous solutions.

\section{Methodology}

An aqueous solution was obtained by dissolving erythromycin powder $(5 \mathrm{~g} / \mathrm{L})$ with $\mathrm{KCl}$ in deionised water. Forward extractions were performed by slowly contacting $10 \mathrm{~mL}$ of $5 \mathrm{~g} / \mathrm{L}$ erythromycin solution with $10 \mathrm{~mL}$ AOT/SB3-18/iso-octane solution in a beaker at room temperature. Solubilization was conducted by stirring the mixtures at $400 \mathrm{rpm}$ for 30 minutes and was left for phase separation (5 hours) to obtain two clear phases. The $\mathrm{pH}$ of the aqueous phase was adjusted with $0.1 \mathrm{M} \mathrm{HCL}$ and $0.1 \mathrm{M} \mathrm{NaOH}$. All experiments were carried out at room temperature.

\section{Analysis}

The concentrations of erythromycin were assayed by absorbance at $485 \mathrm{~nm}$ using UV-Spectrophotometer method (Shimadzu UV-vis). For spectroscopic study, $5 \mathrm{~mL}$ of erythromycin sample was stirred with $5 \mathrm{~mL}$ $27 \mathrm{~N}_{2} \mathrm{SO}_{4}$ for 30 minutes until the solution has changed to orange color. The solution was diluted further before analysis.

\section{Statistical analysis}

The final concentration of erythromycin was established from the organic phase and collected. The statistical analysis was conducted using STATISTICAL software (StatSoft's, data miner) to determine the most significant parameter in the process through pareto chart.

\section{Results and Discussion}

The effect of AOT concentration on erythromycin solubilization was discussed at first. The individual effect of salt concentration and $\mathrm{pH}$ of aqueous phase was analyzed subsequently.

\section{Effect of the AOT concentration}

The effect of MRMS AOT/SB3-18 concentration on erythromycin solubilization in aqueous phase was evaluated and shown in Figure 1. When mixed reverse micelle system (MRMS) of AOT/SB3-18 was used, clear phases were formed and solubilization of erythromycin was produced in higher percentage, up to $98.13 \%$. At $20.0 \mathrm{~g} / \mathrm{L}$ of AOT concentration, erythromycin started to solubilize with $60.90 \%$ percentage transferred. Therefore, it can be assumed that the critical micelle concentration (CMC) of mixed AOT-SB3-18 surfactant is in the range of $0.0-20.0 \mathrm{~g} / \mathrm{L}$ AOT which is lower than CMC of a single AOT $(40 \mathrm{~g} / \mathrm{L}) .{ }^{10}$ Thus, further experiments should be carried out to obtain the accurate CMC value.

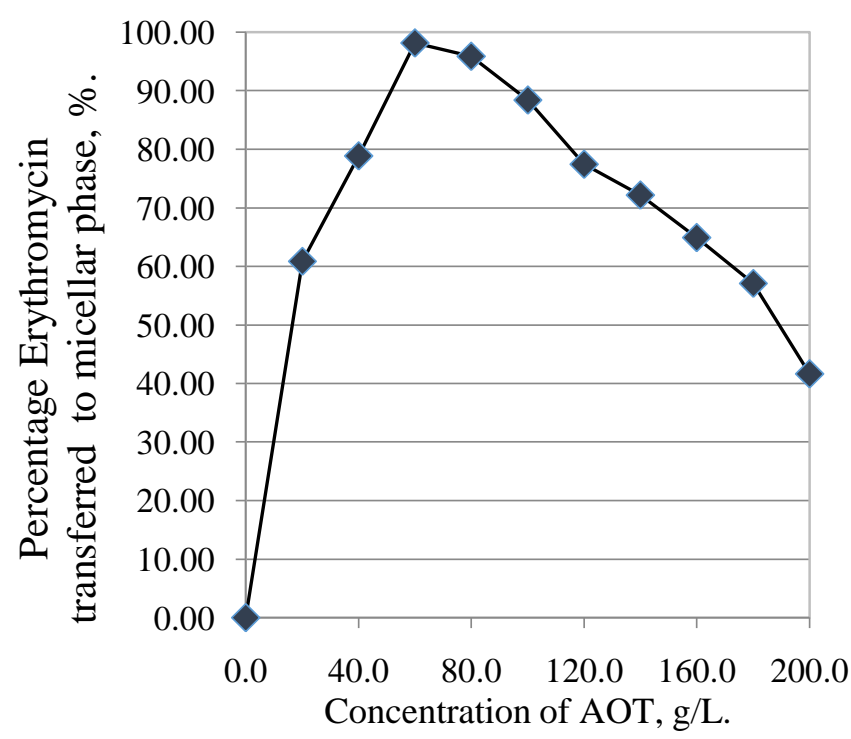

Figure 1: Final concentration of erythromycin, $\mathrm{E}_{\text {of }}$ lies in the organic phase at different surfactant concentrations. Experimental condition: Initial concentration of erythromycin in aqueous phase, $\mathrm{E}_{\mathrm{ai}}$, $5 \mathrm{~g} / \mathrm{L}$; amount of $\mathrm{KCl}, 10 \mathrm{~g} / \mathrm{L}$; molar ratio AOT:SB3$18,10: 1 ; \mathrm{pH}, 8.5 \pm 0.1$; stirring speed, $400 \mathrm{rpm}$; stirring time, 30 minutes; room temperature.

The critical micelle concentration (CMC) is defined as the concentration of a surfactant at which micelles start to aggregate and form micelles in the solution. ${ }^{11}$ When different types of surfactants are mixed together, frequently, it would display synergism or cooperative interactions in their effects on the properties of the system. ${ }^{12}$ This synergism can be attributed to non-ideal mixing effects in the aggregates, which results in CMC of mixed micelle solution that are substantially lower than a pure component alone. ${ }^{13}$ According toNagarajan, ${ }^{14}$ the mixture of ionic and non-ionic surfactants will decrease electrostatic interactions and larger micelles could be formed than using two pure component micelles. Considering the evidence from this study, it has been confirmed that reverse micelles 


\section{Chemical Engineering Research Bulletin 19(2017) 123-128}

extraction is controlled by electrostatic, steric and hydrophobic interactions between the bio-molecules and micelles. ${ }^{15}$ The reduction of interactions in the repulsive head group occurring at the surface resulted in larger sized micelles than in either of the pure component micelles, hence the CMC value of the mixture is also lesser.

The resulted aqueous solution after the solubilization of erythromycin was observed to be a clear solutionwith a transparent interface when the concentration of AOT varied from $20-140 \mathrm{~g} / \mathrm{L}$, thereby indicative of the successful solubilization of erythromycin in the reverse micelle phase. However, increasing the AOT concentration from 80.0-200.0 g/L has significantly lowered the percentage of solubilized erythromycin from $95.87 \%$ to $41.65 \%$ with a slight precipitation observed at the interface of the solution. As clarified by Harikrishna et al., ${ }^{15}$ at high surfactant concentration, the extraction yield would become lower because of intermicellar collision and hindrance to the diffusion of solute by surfactant aggregates. Meanwhile, Juang et al. ${ }^{16}$ appointed that the biomolecule solubilization will increase in conjunction to higher surfactant concentration because of the increment in the size of the micelle. However, larger size indicates reduction of steric hindrance of the reverse micelles and higher degree of large protein molecules transfer, most of which must have been protein contaminants.

The solubilization percentage obtained was in the range of 41.65-98.13\% with the MRMS system. High solubility of erythromycin in mixed micelle solution shows that MRMS technique has a high potential for antibiotic recovery at low surfactant concentration. The presence of zwitterion surfactant was predicted to weaken the surface charge density at the interfacial region hence decreased the inhibitory power of AOT on enzyme. ${ }^{17}$ Previous researchers reported that strong electrostatic interaction between ionic surfactants polar head and protein charges could lead to protein unfolding. ${ }^{18}$ Therefore, to weaken the interaction, zwitterion surfactant molecule was introduced to facilitate the solubilization of erythromycin in the organic phase.

\section{Effect of salt concentration}

The presence of salt is necessary to form stable reverse micelles solution. Salt is also important to reduce the repulsive forces between two surfactant heads which might interfere with the electrostatic interaction between surfactant head group and bio-molecules. The effect of salt concentration of the aqueous phase in the forward extraction process is shown in Figure 2. The percentage of erythromycin transferred into micellar phase was found to increase with $2.0-10.0 \mathrm{~g} / \mathrm{L}$ of $\mathrm{KCl}$ concentration.
According to Zhao et al., ${ }^{19} \mathrm{KCl}$ salt has waterstructure-forming property and causes lesser 'screening' of solutes, therefore is favorable for forward extraction in a reverse micelle. This factor has been the reason $\mathrm{KCl}$ was chosen for this study. The transfer of erythromycin into micellar phase was lesser in accord to raised concentration of $\mathrm{KCl}$ salt from $12.0 \mathrm{~g} / \mathrm{L}$ to $16.0 \mathrm{~g} / \mathrm{L}$ of which could be explained through size exclusion effects.

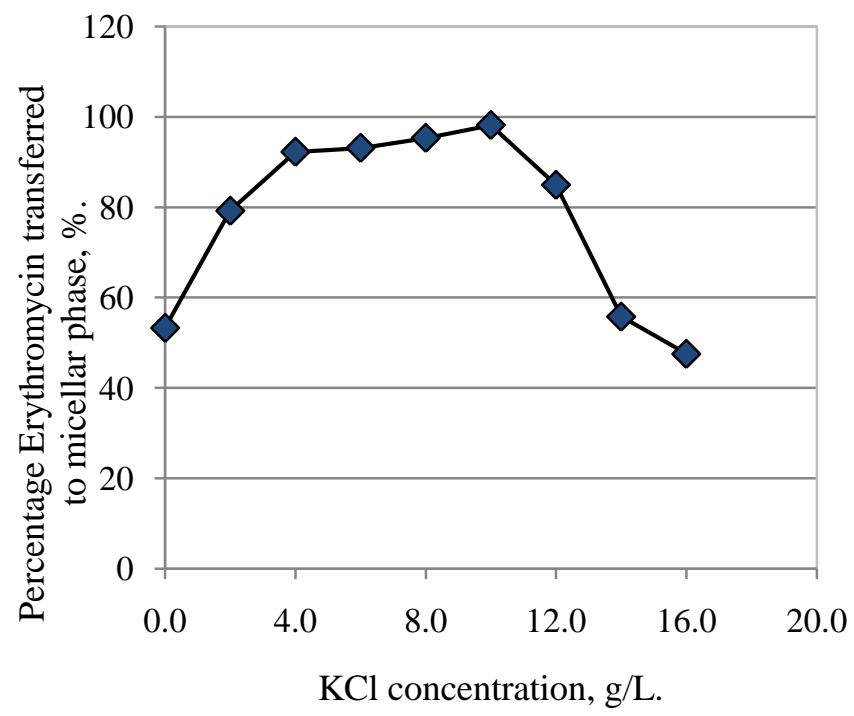

Figure 2: Final concentration of Erythromycin, $\mathrm{E}_{\text {of }}$ lies in the organic phase at different KCL concentrations. Experimental conditions: Initial concentration of Erythromycin in aqueous phase, $\mathrm{E}_{\mathrm{a} i}, 5 \mathrm{~g} / \mathrm{L} ; 60 \mathrm{~g} / \mathrm{L}$ erythromycin concentration, molar ratio AOT:SB3-18, $10: 1 ; \mathrm{pH}, 8.5 \pm 0.1$; stirring speed, $400 \mathrm{rpm}$; stirring time, 30 minutes; room temperature.

As the ionic strength increased, the electric double layer adjacent to the hydrophilic head groups became thinner which resulted in the reduction of the electrostatic repulsion force between the charged head groups of the surfactants. ${ }^{20}$ This effect increased the tendency of smaller reverse micelle droplets in the organic phase (squeezing out effect) and thus the biomolecules with larger sizes were excluded. ${ }^{20}$ This phenomenon is also known as the size exclusion effect.

\section{Effect of the aqueous $\mathbf{p}^{\mathrm{H}}$}

Figure 3 shows the effect of $\mathrm{pH}$ on erythromycin extraction from aqueous solution. The $\mathrm{pH}$ of the solution was adjusted with $1 \mathrm{M}$ HCL \& $\mathrm{NaOH}$. The selected $\mathrm{p}^{\mathrm{H}}$ region for this work was $4-9$. The highest percentage $98.13 \%$ of erythromycin extraction was achieved at approximately $\mathrm{pH} 8.5$, in general. The explanation to this result can be supported with Loh et $a l .^{21}$ and Kawasaki et al. ${ }^{22}$ The erythromycin charge becomes positive as the $\mathrm{pH}$ decreased slightly below the isoelectric point $(\mathrm{pI}), 9.5^{22}$ and negative above $\mathrm{pI}$. Mohd-Setapar et $a l^{23}$ stated that an attractive 


\section{Chemical Engineering Research Bulletin 19(2017) 123-128}

electrostatic interaction between the bio-molecules and the surfactant head groups will only occur when the overall charge of the bio-molecules is opposite that of the charge of the surfactant head groups.

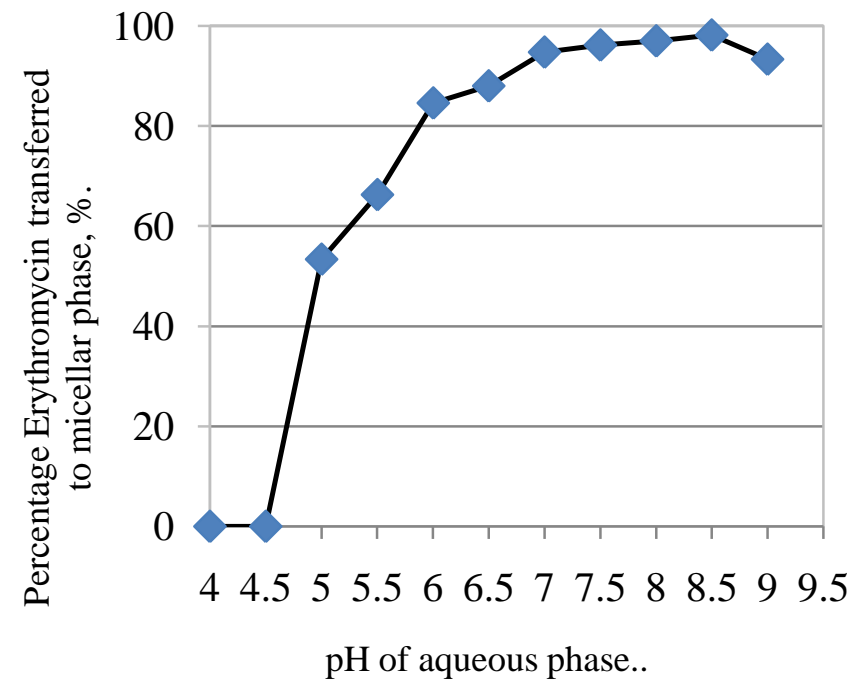

Figure 3: Final concentration of Erythromycin, $E_{o f}$ at different $\mathrm{pH}$ of aqueous phase. Experimental conditions: Initial concentration of Erythromycin in aqueous phase, $\mathrm{E}_{\mathrm{ai}}, 5 \mathrm{~g} / \mathrm{L} ; 60 \mathrm{~g} / \mathrm{L}$ erythromycin concentration, molar ratio AOT: SB3-18, 10:1; stirring speed, $400 \mathrm{rpm}$; stirring time, 30 minutes; room temperature.

Tonova and Lazarova ${ }^{24}$ clarified, solubilization in the forward extraction was governed by the electrostatic interaction between charged protein molecules and charged head group of reverse micelle formed by the surfactant. However, several studies reported that the strong electrostatic and hydrophobic interactions between bio-molecules and ionic surfactant gave negative impact to bio-molecules itself and lowered the extraction yield. ${ }^{25}$ A strong electrostatic interaction between the head group of surfactant and biomolecules will cause a change on the structure of biomolecules and formation of aggregates during the extraction process. ${ }^{17}$

\section{Effect of zwitterion concentration}

Conventionally, AOT is used as a surfactant in reverse micelle extraction. Many reports are often focused on single surfactant rather than the combination of multiple surfactants. The addition of a second surfactant into the ionic surfactant in the organic phase will totally alter the behavior of interfacial region between the organic and aqueous phase. Figure 4 demonstrates the effect of SB3-18 concentration on the final concentration of erythromycin.

It clearly shows that small addition of SB3-18 surfactant into the solution was able to boost up the solubilization of erythromycin in aqueous phase. It was found that adding $5 \mathrm{~g} / \mathrm{L}$ of SB3-18 into the mixture has increased the solubilization of erythromycin from $59 \%$ to $98 \%$. This result is consistent with the finding by Yamada et $a l .{ }^{26}$ which used TWEEN 85 as a second surfactant and suggested that increasing the concentration of TWEEN 85 above $2 \mathrm{mmol} / \mathrm{dm}^{3} \sim$ $0.86 \mathrm{~g} / \mathrm{L}$ under a constant AOT concentration of $50 \mathrm{mmol} / \mathrm{dm}^{3} \sim 22.23 \mathrm{~g} / \mathrm{L}$ will eventually increase the average micellar diameter. Addition of TWEN 85 lowered the surface charge density of reverse micelle and reduced electrostatic and hydrophobic interactions between the AOT head group and the target molecule at the micellar interface.

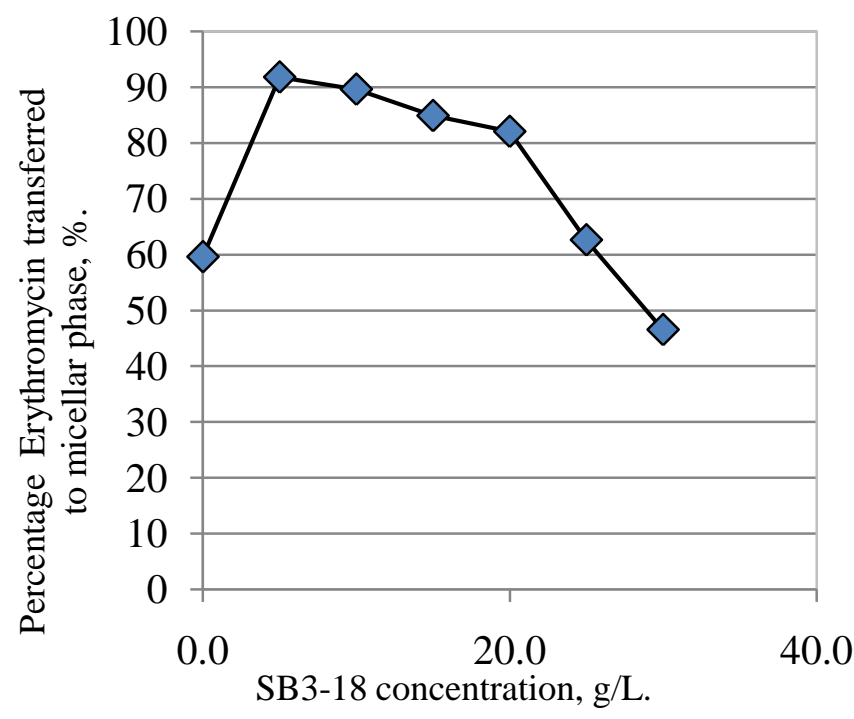

Figure 4: Final concentration of Erythromycin, $\mathrm{E}_{\text {of }}$ at different SB3-18 concentration. Experimental conditions: Initial concentration of Erythromycin in aqueous phase, $\mathrm{E}_{\mathrm{ai}}, 5 \mathrm{~g} / \mathrm{L} ; 60 \mathrm{~g} / \mathrm{L}$ erythromycin concentration; $\mathrm{pH}, 8.5 \pm 0.1$, stirring speed, $400 \mathrm{rpm}$; stirring time, 30 minutes; room temperature.

\section{Pareto chart}

A Pareto chart in Figure $6 \mathrm{can}$ be utilized to graphically summarize and display the significant effect of each independent variables on the solubilization of erythromycin in mixed AOT:SB3-18 reverse micelle. The chart demonstrates each estimated effects in descending order of magnitude. The vertical line in the Pareto chart indicates the magnitude of statistical significance of each effect. Any bar that extends beyond the line corresponds to any effect that is statistically significant, at $95.0 \%$ confidence level.

The result shows that AOT concentration and Zwitterion concentration provided the most dominant effect on the solubilization of erythromycin from aqueous to organic phase by a factor of 4.562 .

As stated by Soni et al. ${ }^{27}$ the surfactant concentration is already identified to affect the reverse micellar size. 


\section{Chemical Engineering Research Bulletin 19(2017) 123-128}

By increasing surfactant concentration, reverse micelle size is increased. ${ }^{28}$ Therefore, more biomolecules are able to solubilize in the polar core or reverse micelle. The contributing factors, in a descending order are zwitterion concentration > AOT concentration > Aqueous $\mathrm{pH}>\mathrm{NaCl}$ Concentration.

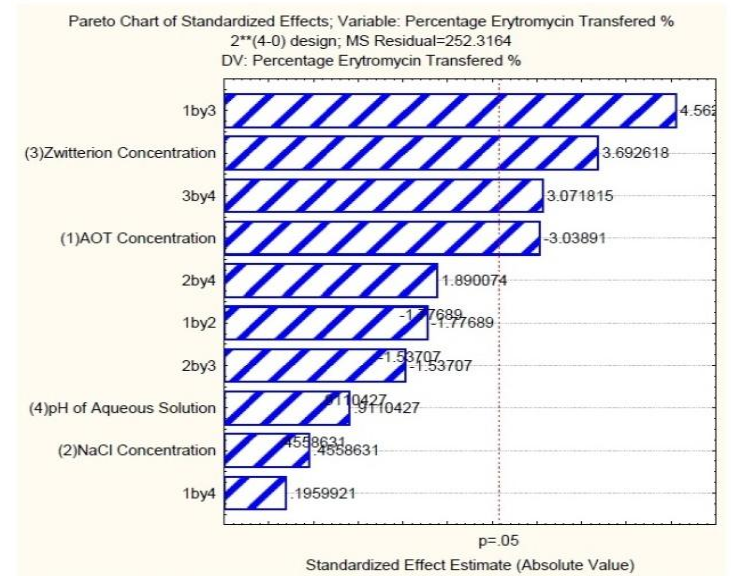

Figure 6: Pareto chart indicating the significance level for each parameters for response.

\section{Conclusion}

Experiments on the solubilization of erythromycin into mixed reverse micelles of AOT and SB3-18 have been carried out. Forward extraction was performed with MRMS and satisfactorily resulted in good solubilization of erythromycin with regards to percentage of erythromycin transferred. The results remark that surfactant concentration is the important parameter affecting the solubilization of erythromycin into mixed reverse micelle phase. It was found that extracting erythromycin using AOT reverse micelle system will not occur without sufficient AOT and SB3-18 concentration. In this study, $20.00 \mathrm{~g} / \mathrm{L}$ was the minimum amount of AOT required. The maximum erythromycin transferred $(98.13 \%)$ was obtained at $60.0 \mathrm{~g} / \mathrm{L}$ AOT concentration. Solubilization of erythromycin was found to be higher at $\mathrm{pH} 8.5$, salt concentration $10 \mathrm{~g} / \mathrm{L}$ and $5 \mathrm{~g} / \mathrm{L}$ of SB3-18. The solubilization of erythromycin was found to be in the order of zwitterion concentration $>$ AOT concentration $>$ Aqueous $\mathrm{pH}>\mathrm{NaCl}$ Concentration. The present findings proved that erythromycin can be successfully solubilized in MRMS, thereby remarks a wider relevance for the subsequent step of backward extraction (recovery process).

\section{Acknowledgement}

Support from the Department of Technology, Universiti Malaysia Pahang and financial aid from MOHE.

\section{References}

1. Z. Wenjian, C. Kui, Z. Jiawen, and J. Lijun,“A novel process for erythromycin separation from fermentation broth by resin adsorption-aqueous crystallization," Separation and Purification Technology, vol. 116, pp. 398-404, 2013.

2. 2.K. Fahimeh, A. Hossein, N. Sanaz, and G. Masoumeh, "Determination of erythromycins in fermentation broth using liquid phase extraction with back extraction combined with high performance liquid chromatography," Arabian Journal of Chemistry, vol.7, no. 3, pp. 292296,2014 .

3. L. Zhou, Q. Feng, B. Hao and G. Xueqiang, "Study on new solvent extraction systems for erythromycin," Journal of Chemical Technology and Biotechnology, vol.80, no. 7, pp. 772781,2005 .

4. S. H. Krishna, N. D. Srinivas, K. S. M. S. Raghavaraoand N. G. Karanth, "Reverse micellar extraction for downstream processing of proteins/enzymes," Advances in Biochemical Engineering/Biotechnology, vol. 75, pp. 119-83, 2002.

5. D. Xin, C. Juan and G. Xia, "Extraction of ovalbumin with gemini surfactant reverse micelles - effect of gemini surfactant structure," Separation and Purification Technology,vol.158, pp. 367-373, 2016.

6. W. Jing, G. Jingjing, M. Zhitong and G. Xia, "Reverse micellar extraction of bromelain from pineapple peel - effect of surfactant structure,'Food Chemistry, vol.197, pp. 450-456, 2016.

7. S. Kumar, A. B. Hemavathi and H. U. Hebbar, "Affinity based reverse micellar extraction and purification of bromelain from pineapple (Ananas comosus L. Merryl) waste," Process Biochemistry, vol.46, no. 5, pp. 1216-1220,2011.

8. C. C. Sing, S. H. Mohd-Setapar, S. N. MohamadAziz and V. M. Starov, "A new method of extraction of amoxicillin using mixed reverse micelles," Colloids and Surfaces A: Physicochemical and Engineering Aspects, vol.460, 137-144, 2014.

9. A. A. Tzialla, A. A. Taha, E. Kalogeris and H. Stamatis, "Improving the catalytic performance of fungal laccases in monoterpene-based reaction systems, "Biotechnology Letters, vol. 31,no. 9, pp. 1451-1456, 2009.

10. J. Fu, Z. Cai, Y. Gong, S. E. O’Reilly, X. Hao and D. Zhao, "A new technique for determining critical micelle concentrations of surfactants and oil dispersants via UV absorbance of pyrene," Colloids and Surfaces A: Physicochemical and Engineering Aspects, vol.484, pp. 1-8, 2015. 


\section{Chemical Engineering Research Bulletin 19(2017) 123-128}

11. S. H. Mohd-Setapar, S. H. Wakeman, and E. S. Tarleton, "Penicillin G solubilisation into AOT reverse micelles," Chemical Engineering Research and Design, vol.87, no. 6, pp. 883-842, 2009.

12. S. R. Patil, N. Buchavzov, E. Careya, and C. Stubenrauch, "Binary mixtures of BDodecylmaltoside (B-C12G2) with cationic and non-ionic surfactants: micelle and surface compositions," Soft Matter,vol.4, no. 4,pp. 840848, 2008.

13. G. Sharma and A. Z. Naqvi,"Micellization and interfacial behavior of binary surfactant mixtures based on cationic geminis and nonionic tweens," Colloids and Surfaces A: Physicochemical and Engineering Aspects, vol. 385, no. 1, pp. 6370,2011 .

14. R. Nagarajan, "Molecular theory for mixed micelles," Langmuir, vol.1, no. 3, pp.331-341, 1985.

15. S. Harikrishna, N. D. Srinivas, , K. S. M. S. Raghavarao, and N. G. Karanth, "Reverse micellar extraction for downstream processing of protein/enzymes," Advances in Biochemical Engineering/Biotechnology, vol. 75, pp. 119-183, 2002.

16. R. -S. Juang, H. -L. Chen and S. -C. Tsao, "Recovery and separation of surfactin from pretreated bacillus subtilis broth by reverse micellar extraction," Biochemical Engineering Journal,vol.61, pp. 78-83, 2012.

17. A. B. Hemavathi, H. Umesh Hebbar and K.S.M.S. Raghavara, "Mixed reverse micellar systems for extraction and purification of $\beta$-glucosidase," Separation and Purification Technology, vol.71, no. 2, pp. 263-268, 2010

18. S. Doussin, N. Birlirakis, D. Georgin, F. Taran and P. Berthault, "Novel zwitterionic reverse micelle for encapsulation of proteins in low-viscosity media. Chemistry," A European Journal, vol. 12, no. 15,pp. 4170-4175, 2006.

19. L. Zhou, S. M.Budge, A. E. Ghaly, M. S. Brooks and D. Dave, "Extraction of chymotrypsin from red perch (sebastes marinus) intestine using reverse micelles: optimization of the backward extraction step," Journal of Bioprocessing \& Biotechniques, vol. 2, no. 3, pp. 120-128, 2012.
20. K. E. Nandini, and N. K. Rastogi, "Reverse micellar extraction for downstream processing of lipase: effect of various parameters on extraction,'Process Biochemistry,vol.44, no. 10, pp. 1172-1178, 2009.

21. K. H. Loh, S. E. Lau, S. H. Setapar, K. S. N. Kamarudin, N. Othman, A. N. Sadikin and H. B. Mat,"Reverse micelle extraction of erythromycin," Perak, Proceedings of the $8^{\text {th }}$ Symposium of Malaysia Chemical Engineers, 2004.

22. J. Kawasaki, R. Egashira, T. Kawai, H. Hara and L. Boyadzhiev, "Recovery of erythromycin by a liquid membrane," Journal of Membrane Science, vol.112, no. 2, pp. 209-217, 1996.

23. S. H.Mohd-Setapar, R. J. Wakeman, and E. S. Tarleton, "Penicillin G solubilisation into AOT reverse micelles," Chemical Engineering Research and Design,vol.87, no. 6, pp. 883-842, 2009.

24. K. Tonova and Z. Lazarova, "Reversed micelle solvents as tools of enzyme purification and enzyme-catalyzed conversion," Biotechnology Advances, vol.26, no. 6, pp. 516-532, 2008.

25. D. M. F. Prazeres, F. A.P. Garciab, and J. M. S.Cabral, "Kinetics and stability of a Chromobacterium viscosum lipase in reversed micellar and aqueous media," Journal of Chemical Technology and Biotechnology, vol. no. 2, 53,pp. 159-164, 1992.

26. 26.Y. Yamada, R. Kuboi and S. Komazawa, "Increased activity of chromobacterium viscosum lipase in aerosol AOT reverse micelles in the presence of nonionic surfactants," Biotechnology Progress, vol. 9, pp. 468-472, 1993.

27. K. Soni and D. Madamwar, "Reversed micellar extraction of an extracellular acid phosphatase from fermentation broth," Process Biochemistry, vol. 36, no. 4, pp. 311-315, 2000.

28. Q.Chang, H.Lui, J.Chen. "Extraction of lysozyme, a-chymotrypsin, and pepsin into reverse micelles formed using an anionic surfactant, isooctane and water,'Enzyme and Microbial Technology, vol. 16, no. 11, pp. 970-973, 1994.

\section{Available online at http://www.banglajol.info/index.php/CERB}

Publisher: Department of Chemical Engineering, Bangladesh University of Engineering and Technology (BUET). Review \&Publication: A submitted original manuscript is taken into review only if the uniqueness is found to be more than $85 \%$ in plag-scanning and selected for publication by the complete acceptance from at least two reviewers out of three. Home Page: http://www.banglajol.info/index.php/CERB . Indexed by Chemical Abstract Service (CAS), CEABA-VtB, Google Scholar, Scopus and DOAJ. 